\title{
Overload of families taking care of elderly people with Alzheimer's Disease: a comparative study
}

\author{
Ana Carla Borghi ${ }^{1}$ \\ Vivian Carla de Castro 1 \\ Sonia Silva Marcon² \\ Lígia Carreira ${ }^{3}$
}

Objective: to compare the overload of the main and secondary family carers of patients with Alzheimer's Disease, and identify which dimension generates most impact. Method: a comparative study conducted in the city of Maringá, State of Paraná, with 20 primary carers of elderly patients with Alzheimer's Disease and 20 secondary caregivers. The data was collected in May and June 2012, using the Scale for Assessment of Overload of Members of Psychiatric Patients' Families (FBIS-BR), and the results were analysed using the Mann-Whitney test and analysis of variance. Results: the global objective overload, and also in each subscale, was significantly greater in the group of main caregivers; the subjective overload showed no difference between the groups. Comparing the subscales, the routine assistance provided to the patient had greater influence on objective overload in both groups, and the concern with the elderly patient was the dimension that had most influence on the subjective overload of main caregivers and also of secondary caregivers. Conclusion: the differences in overload between the different groups reinforces the need for planning of health care actions for each type of caregiver, seeking to reduce these differences.

Descriptors: Caregivers; Alzheimer Disease; Family.

\footnotetext{
${ }^{1}$ Master's students, Departamento de Enfermagem, Universidade Estadual de Maringá, Maringá, PR, Brazil. ${ }^{2} \mathrm{PhD}$, Associate Professor, Departamento de Enfermagem, Universidade Estadual de Maringá, Maringá, PR, Brazil. ${ }^{3} \mathrm{PhD}$, Adjunct Professor, Departamento de Enfermagem, Universidade Estadual de Maringá, Maringá, PR, Brazil.
} 


\section{Introduction}

As a result of the ageing process among the population, we have witnessed a significant increase in the occurrence of chronic degenerative diseases, among which we highlight types of dementia, the most prevalent of these being Alzheimer's Disease $(A D)^{(1-3)} . A D$ is characterised as being a chronic and degenerative brain disease, which is progressive and irreversible, which starts insidiously and is characterised by a gradual loss of cognitive function and also affective and behavioural disorders(1,3-4), jeopardising the physical, mental and social integrity of the chronologically advantaged patient, which requires care of greater and greater complexity, nearly always related to family dynamics(2). Therefore, special mention is given to the importance of the family in the process of provision of care to this chronologically advantaged patient, due to the fact that, as the illness worsens, there is greater demand for care and for constant supervision, a role which is normally carried out by a family member ${ }^{(1,4-6)}$.

This condition of dependence of the patient may affect all the members of the family ${ }^{(1)}$, especially those people who have directly taken over the responsibility of caring for the patient. In this regard, we can consider two types of caregivers: the main caregiver - who has either all or most of the responsibility for taking care of the chronologically advantaged person in the home, and the second caregiver - a family member, volunteer or hired person who provides care and assistance in complementary activities ${ }^{(7)}$.

Recent studies have shown that the modifications in the life of the caregiver may lead to physical, emotional and financial overload ${ }^{(4,6,8-10)}$ and also interfere with social relationships and leisure ${ }^{(8-10)}$. The overload of the caregiver may lead to acute and chronic illnesses and, as a result, the use of a range of medication, making the caregiver just as ill as the chronologically advantaged person who has Alzheimer's Disease ${ }^{(4)}$. The caregiver is usually not prepared to take over full responsibility for giving care and other responsibilities as required, and thus needs to be duly prepared to take them over(11), and also needs support to carry out the task.

It is therefore quite relevant to study the existing differences between the groups of main caregivers and secondary caregivers, in relation to the overload experienced in the provision of care to an elderly patient with Alzheimer's Disease. The impact arising from providing such care can have negative and positive consequences, which explains the variability that exists between caregivers. Therefore, based on the assessment of the level of overload of different groups of caregivers, one can contribute so that the professionals working in the health sector, particularly the nurse, may more effectively direct the assistance provided to these people, particularly during care guidance., giving them a base for the important assistance to their families, their daily organisation and also the division of the tasks involved in taking care of the patient.

The analysis of the overload is an essential instrument for the professional and leads to a diagnosis which allows the provision of essential care together with the caregiver of the chronologically advantaged patient with Alzheimer's Disease. The importance of the development of comparative studies, within the standard of care provided to the dependent elderly patient, seeks the establishment of strategies that allow an improvement in the life of the person who provides care and also of the person who receives the care. In this regard, the purpose of the presented study is to compare the overload of the main family caregiver with the secondary caregiver, for a person of advanced age with Alzheimer's Disease, and also to identify which dimension has a greater impact on the overload.

\section{Method}

The present comparative study was carried out with participants in the Brazilian Alzheimer's Disease Association (Associação Brasileira de Alzheimer ABRAZ), in the regional subchapter of the city of Maringá, State of Paraná. This association was created in 1993, with regional chapters in twenty-two Brazilian States, and is a non-profit organisation comprising families of $A D$ patients and also professional people working in the humanities, in the health area, social workers and volunteers.

The study has also included family caregivers who give care to chronologically advantaged family members who have been diagnosed with DA who participate, or who have participated, in ABRAZ meetings over the last two years. The ABRAZ meetings are held every month and have an average attendance of 13 people, including family members of chronologically advantaged people with Alzheimer's Disease, guests and volunteers. The selection of the participants was intentional and occurred based on minutes with study of the family members who had attended meetings during the last two years $(n=68)$. The contacts for participation in the study were made personally with those people who turned up at the 
last two meetings, when the researchers were present, and also by telephone, and out of these subjects six were excluded due to the death of the family member, five because they had no information about telephone numbers or address on the attendance sheets of the meetings, tem who could not be found after three attempts, and seven who refused. This means that the final composition of the study universe was 40 subjects remaining, divided into two groups, which have been named as follows: (a) $G_{\text {CuID }} A$ - consists of 20 main family caregivers providing care for elderly relatives with $A D$; (b) $G_{\text {CUID }} B$ - consists of 20 secondary carers providing care for elderly relatives with $A D$.

The data was collected in May and June 2012, by means of a structured interview, previously scheduled, in line with the availability of the interviewee and taking place at the patients' homes, using two different instruments: a social and demographic file for the characterisation of the caregiver, and also the use of the Scale for Assessment of Family Members' Overload (FBIS-BR), duly translated and adapted for the Brazilian culture, and comprising five subscales which appraise, based on the last 30 days, five different dimensions of the overload experienced by families of psychiatric patients: a) assistance in the daily routine of the patient; b) supervision of problematic behaviour in the patient; c) financial expenses that the family member has had with the patient; d) impact on daily routine of the family; e) concerns for the patient, as expressed by the family member(12).

These five dimensions of the scale allow the appraisal of objective and subjective overload. The objective overload is established based on the frequency of assistance and supervision within the routine care for the patient and also changes in the life routine; subjective overload is established based on the degree of discomfort felt by the family member on exercising the role of caregiver and also concerns for the patient ${ }^{(12)}$. As the FBIS-BR does not have a previously established cut-off point, the recommendations of the validators have been followed, meaning that the overload is established based on the median value of the scores in each subscale, except for subscale $C$ which addresses aspects related to financial resources ${ }^{(12)}$.

For the analysis of data, the software used was the Statistica software package, version 8.0, and with the confirmation of non-Gaussian distribution of the data (using the Kolmogorov-Smirnov test for this purpose) in relation to the characteristics of the sample and the overload scores, the Mann-Whitney test was used, followed by the Spearman correlation test $(r)$ in the cases where the groups had different characteristics. Analysis of variance (ANOVA) was also used, as also the multiple comparison Kruskal-Wallis test to identify which dimension had greatest influence on overload. In all analyses, a significance level of $5 \%$ was considered.

The project for this study was approved by the Permanent Research Ethics Committee for Research using Human Subjects at the State University of Maringá (Opinion No. 29,372). All the participants signed a free and informed consent form in two copies.

\section{Results}

The participants in $\mathrm{G}_{\text {CuID }} A$ were mostly female $(n=19)$, with ages between 31 and 71years with a mean age of 52.7 years, and occupied family positions as follows: son or daughter $(n=10)$, wife $(n=7)$, sister $(n=2)$ and daughter-in-law $(n=1)$. The mean time spent as a caregiver was seven years, with a minimum of three years and a maximum of eleven years. Out of these caregivers, only nine received help from other family members in providing care for the elderly patient - mainly daughters, sisters, sisters-in-law and nieces.

The caregivers in the group known as $G_{\text {CuID }} B$ had ages between 22 and 75, with a mean age of 48.6 years. Most of them were women $(n=17)$ and occupied the family position of sons or daughters $(n=8)$, wives $(n=8)$, daughter-in-law $(n=2)$ and grand-daughter $(n=2)$, in relation to the patient. The mean time spent as a secondary caregiver was four years and three months, with the minimum being one year and the maximum being six years.

In the comparison between the groups, it was verified that there was no statistically significant difference in terms of age, but the groups did differ in terms of time spent on care. Here we mention that 14 pairs of caregivers (considering one main and one secondary caregiver) were relatives of one same chronologically advantaged patient with Alzheimer's Disease, totalling 28 carers. The other 12 were relatives of 12 different elderly DA patients.

On analysing the data presented in Table 1 , we see a statistically significant difference $(p=0,005)$ between the medians of the scores for global objective overload between groups of caregivers, being greater in the case of the $\mathrm{G}_{\text {CuID }} A$ group. The same phenomenon was observed in relation to its three subscales $(p=0.008,0.034$ and 0.004 , respectively for subscales $A, B$ and D). 
The overload for assistance to the patient in his or her daily routine (objective subscale $A$ ) was greater $(p=0.004)$ for primary caregivers $\left(G_{\text {CUID }} A\right)$, as these provided assistance more often in relation to bathing, application of medication, management of income and medical care, compared to the $\mathrm{G}_{\text {CUID }} B$ group.

In relation to the supervision of problematic behaviour patterns (objective subscale $B$ ), the overload was larger $(p=0.034)$ for the $G_{\text {CUID }} A$ group which, as a result of daily coexistence with the patient of advanced age, more frequently faced situations of insults, aggression and other shameful situations. Finally, objective subscale $D$, which refers to the impact that the caregivers suffers in his or her daily routine, shows that the overload has also been greater for the group known as $G_{\text {CuID }} A(p=0.004)$, because, due to the greater degree of responsibility towards the elderly patient, the caregivers in this group, more than those of the other group $G_{\text {CuID }} B$, often did not show up or arrived late for their appointments, did not embark on leisure activities, changed the routine of the homes and reduced the attention devoted to other family members.

Table 2 shows that the sizes of the subscales bring different overload levels in the two groups of caregivers $\left(p=0.002\right.$ and $p=0.007$ respectively for the $G_{\text {CUID }} A$ and $G_{\text {CUID }} B$ groups). On proceeding with the multiple comparison of Kruskal-Wallis, a significant difference was identified $(p=0.002)$ only between the subscales $A$ and $B$ of objective overload in $G_{\text {CUID }} A$, with greater overload related to assistance to the patient in his or
In relation to the subjective global overload (Table 1) no statistically significant differences were observed between the groups of caregivers $(p=0.357)$, and neither in any of the subscales $A, B$ and $E(p=0.607$ $0.152 ; 0.8$ respectively).

Table 1 - Median global scores and those of objective and subjective subscores on the FBIS-BR scale, and the value of $p$ for the groups of caregivers

\begin{tabular}{ccccc}
\hline & & \multicolumn{2}{c}{ Medians } & Mann-Whitney \\
\cline { 2 - 4 } \multicolumn{2}{r}{ Scale/Subscale } & $\mathbf{G}_{\text {cuID }}$ A & $\mathbf{G}_{\text {cuID }}$ B & p \\
\hline \multicolumn{2}{c}{ Objective overload } & 3.0 & 2.0 & $0.005^{*}$ \\
A & Objective & 5.0 & 3.0 & $0.008^{*}$ \\
B & Objective & 2.0 & 1.0 & $0.034^{*}$ \\
D & Objective & 3.8 & 2.0 & $0.004^{*}$ \\
Global subjective overload & 2.0 & 1.0 & 0.357 \\
A & Subjective & 1.0 & 1.0 & 0.607 \\
B & Subjective & 1.8 & 1.0 & 0.152 \\
E & Subjective & 3.5 & 3.0 & 0.8 \\
\hline
\end{tabular}

$* \mathrm{p}<0.05$

her daily routine, rather than in the supervision of problem behaviour. In the same manner, $G_{\text {CuID }} B$ has also shown a statistically significant difference only between the objective subscales $A$ and $B(p=0.008)$, which shows that, regardless of whether the caregiver is main or secondary, the main overload related to care giving lies in assistance to the patient, in his or her daily life routine.

Table 2 - Analysis of the differences between the medians of objective subscales $A, B$ and $D$, and between the medians of subjective subscales A, B and E of the FBIS-BR

\begin{tabular}{|c|c|c|c|c|c|c|c|c|c|c|c|c|c|c|}
\hline \multirow{3}{*}{$\begin{array}{l}\text { Family } \\
\text { Relative }\end{array}$} & \multirow{2}{*}{\multicolumn{3}{|c|}{$\begin{array}{c}\text { Median } \\
\text { Objective } \\
\text { Subscales }\end{array}$}} & \multirow[b]{2}{*}{ ANOVA } & \multirow{2}{*}{\multicolumn{3}{|c|}{$\begin{array}{l}\text { Multiple Comparisons of } \\
\text { Kruskal-Wallis }\end{array}$}} & \multirow{2}{*}{\multicolumn{3}{|c|}{$\begin{array}{c}\text { Median } \\
\text { Subjective } \\
\text { Subscales }\end{array}$}} & \multirow[b]{2}{*}{ ANOVA } & \multirow{2}{*}{\multicolumn{3}{|c|}{$\begin{array}{l}\text { Multiple Comparisons of } \\
\text { Kruskal-Wallis }\end{array}$}} \\
\hline & & & & & & & & & & & & & & \\
\hline & A & B & D & $p$ & $p(A B)$ & $p(A D)$ & $p(B D)$ & A & B & $E$ & $p$ & $p(A B)$ & $p(A E)$ & $p(B E)$ \\
\hline $\mathrm{G}_{\text {CUID }} \mathrm{A}$ & 5.0 & 2.0 & 3.8 & $0.002^{*}$ & $0.002^{*}$ & 0.58 & 0.11 & 1.0 & 1.8 & 3.5 & $0.00^{*}$ & 0.74 & $0.00^{*}$ & $0.00^{*}$ \\
\hline$G_{\text {CUID }} B$ & 3.0 & 1.0 & 2.0 & $0.007^{*}$ & $0.008^{*}$ & 0.75 & 0.2 & 1.0 & 1.0 & 3.0 & $0.00^{*}$ & 1 & $0,00^{*}$ & $0,00^{*}$ \\
\hline
\end{tabular}

${ }^{*} \mathrm{p}<0.05 ; A B$ : subscales $A$ and $B ; A D$ : subscales $A$ and $B ; B D$ : subscales $B$ and $D ; A E$ : subscales $A$ and $E ; B E$ : subscales $B$ and $E$

In relation to the subjective overload, we have seen a significant difference for the two groups of caregivers $(p=0.00$ for both). In multiple comparisons, we have observed that both in $\mathrm{G}_{\text {CUID }} A$ and in $\mathrm{G}_{\text {CUID }} B$ the concern for the chronologically advantaged person (subscale $E$ ) was statistically greater than the degree of inconvenience felt when helping the patient in his or her daily routine (subscale A), or on supervising the patient's problem behaviour (subscale B), with a p-value of 0.00 for all cases. However, we have not observed any significant 
difference between subscales $A$ and $B(p=0.74)$. These results show that the concern with the chronologically advantaged patient is the main factor related to the subjective overload in the two classes of caregivers.

Although the time as a caregiver is significantly longer in $G_{\text {CUID }} A(p=0.0002)$, only the objective dimension - impact on daily routine (subscale $D$ ) in $\mathrm{G}_{\text {CUID }} \mathrm{B}$ has shown a positive correlation between the time spent as a carer and the overload ( $r=0.589$; $\mathrm{p}=0.0006$ ).

Finally, out of the 40 people interviewed, only nineteen answered the questions about financial expenses (subscale $\mathrm{C}$ ), twelve main caregivers and seven secondary caregivers. Among the caregivers of the $G_{\text {CuID }} A$ group, the average monthly expenses with the elderly patient came to 1.4 minimum wages, a sum spent mainly on the purchase of medication and nappies, as well as medical treatment, food, housing and clothes. It is important to stress that seven out of the 12 main caregivers consider that the expenses with the chronologically advanced patient do not overload the family budget, and four of these people have mentioned that the senior citizen's retirement pay (on average one national minimum wage) covered part of these expenses.

In relation to the secondary caregivers, the average monthly expenses incurred with the senior citizen were less than one minimum wage, and were used for the same purpose. However, here we highlight that five of the seven secondary caregivers reported that the monthly expenses with the senior citizen rarely or sometimes overloaded the family budget, different from what was reported by the caregivers of the GCUID A group for which, in spite of mentioning a lower average expense, these expenses do not have so much impact on the family budget.

\section{Discussion}

The participants of the two groups of caregivers have a similar profile to that described in national and international literature, being mostly women, occupying the family role of daughter or wife of the patient ${ }^{(6,13-14)}$ and are exclusively dedicated to taking care of the sick relative ${ }^{(13)}$. This fact could be related to the social and cultural role of the woman in society, as the responsibility for caring for the children makes them better prepared to take on this role, while the man normally remains as the breadwinner for the family(15-16). However, the ever greater insertion of women on the labour market has reduced the time they have available for such activities ${ }^{(2)}$, which, to a certain extent, puts men closer to caring for family members with $A D^{(15)}$ and, at the same time, means that women also carry out the role of secondary caregiver. It must also be mentioned that female caregivers normally suffer greater impact than men, as they take on tiring tasks more often - the hygiene of the patient, apart from having to manage domestic tasks ${ }^{(3,17)}$.

The positive correlation between the time spent as a caregiver within the $G_{\text {CUID }} B$ group and the overload related to the dimension of impact on daily routine (subscale $D$ ) could be related to the fact that the secondary caregivers keep their jobs and, for this reason, feel the effects of the changes more, however small they may be; in the case of primary caregivers, as they are more accustomed to care and, also, as they centralise their activities around them, do not feel the overload arising from those activities which they consider their work or obligation, with so much impact. In other studies ${ }^{(10,18)}$ there has been no identification of any correlation between age and overload, confirming the findings of this study.

The greatest degree of objective overload in the $\mathrm{G}_{\text {CuID }}$ A group confirms the results held in other studies ${ }^{(19)}$, showing, even with the significant participation of the family as a whole, that in general the caregiver changes his or her routine to take care of the chronologically advantaged person with $A D$, and the responsibility for direct care is in many cases let with one sole family member, for whom this activity becomes extremely tiring and stressful.

In fact, the main caretaker experiences a break in his or her normal lifestyle, which is characterised, for example, due to the lack of borders separating the caregiver's life and that of the patient, which means that there is less time for leisure, social life, family activities and affective pursuits - and, in many cases, economic problems $^{(2)}$. This all interferes with self-care and quality of life, and this could give rise to feelings of depression, anguish, anger, sadness, fear, guilt and frustration ${ }^{(4,20)}$. The study shows that these caregivers have a greater chance of showing psychiatric symptoms and health problems, including arterial hypertension, digestive disorders and breathing problems, and depression, as well as experiencing family conflicts and problems at work with greater frequency, compared with people of the same age who do not carry out such a role(17).

This stressful condition tends to increase, as the elderly people with $A D$ become progressively more 
dependent. In this regard, the inclusion of the family in the planning of care actions from the moment of the diagnosis of $A D$ could reduce the vulnerability of the chronologically advantaged and also their care-giving relatives, as, when informed about the illness as also its progression, and made aware of the superimposition of roles and its consequence, there is the possibility of preparing, reorganisation to face the changes that shall certainly come, and this shall have positive consequences for the coexistence between family members ${ }^{(2,20)}$. However, supporting the caregivers does not mean only giving information and guidance about the illness and appropriate care ${ }^{(4)}$. There is also a need to promote and maintain a social support network for these families, so that the responsibility for the care of the patients may be divided, reducing the overload that are inherent to these roles. The groups of mutual help connected to ABRAZ are a good example of the activities of this network ${ }^{(2)}$.

On comparing the overload of the groups of caregivers by subscale, the differences found also referred to the objective overload. In all subscales ( $A, B$ and $D$ ) the caretakers of the $G_{\text {CUID }} A$ group had a higher degree of overload than $G_{\text {CUID }} B$, which could be justified by a greater time spent as a caregiver of the $G_{\text {CUID }} A$ group, with the ill elderly patient. It is the main caregiver that takes on greater responsibility both in the provision of regular care as also in the supervision of problem behaviour patterns and, as a result, suffers greater impact from the tasks of the caregivers in daily activities. It is worth pointing out, however, that in spite of the objective overload being larger for the carers in the $\mathrm{G}_{\text {CUID }}$ A group for all subscales, the components of subscale $A$ showed a greater influence in the establishment of the overload arising from care-giving when compared with those of subscale $B$. This can be understood based on the understanding that the tasks that are involved in essential care - the personal hygiene and the feeding of the patient (components of subscale A) - have more wearing characteristics and also tend to become more complex as the illness progresses and the level of dependence increases ${ }^{(2-3)}$.

In the subjective sphere, no statistically significant difference has been observed between the overload of the caregivers of both groups, which arises, on the one hand, from the fact that the caregivers in $G_{\text {CUID }} B$ only stay with the patient with $A D$ for a short period of time, and thus do not feel overloaded; and, on the other hand, the fact that the caregivers in the $G_{\text {CUID }} A$ group, despite the greater dedication to the sick patient, have reported little discomfort when dealing with the stressful situations enforced by the role that has been taken on. The literature shows that this could be related to the double feeling generated by the coexistence with the sick patient; that is, while the caretaker is taken over with rage, the patient being stubborn, the caregiver also feels pity for having a family member afflicted by a progressive disease(20)

In addition, the low perception of the subjective overload by the caregivers in the $\mathrm{G}_{\text {CuID }} A$ group can also be linked to a feeling of gratitude and the desire to show love for the family member by means of care, concern, respect and solicitude, which leads the caregivers to carry out the caretaking activities in a loving and patient manner(2). This fact leads us to doubt the assumption that the stress of the caregivers is a natural and inevitable event, as the subjective assessment of care is heterogeneous, and also reductionist; therefore, the direct association of the demands associated to care with also the harm to the health of the caregivers( ${ }^{(7)}$.

In relation to the financial aspect, it has been found that the expenses with elderly people with $A D$ are not a burden on the budget for the main caregivers, but is in the case of secondary caregivers. Even though $A D$ is, in fact, a financial burden on the family which has additional expenses with medication, utensils for daily hygiene, comfort and food, and also expenses related to support in treatment(2), for the main caregivers these expenses are compensated, to a certain extent, with the funds arising from the retirement pay of the elderly patient. In the case of secondary caregivers, the expenses are more representative because they help almost exclusively with the financial side.

Even though the instruments used do not identify the income of the caregivers as an inherent aspect in the analysis of overload, it is possible to reach the conclusion that subjective heterogeneity with which caregivers perceive the situation they are experiencing, such as the fact that they take care of a sick family member as an obligation or in return for the care and patience which they received one day, could also justify the distinct perception by these two groups, in relation to the influence on the accounting of the expenses with $A D$ within the family budget. However, different from the results of this study, the financial overload was made evident in another study as being one of the factors that has most contributed towards the overload of the caregivers ${ }^{(19,21)}$, especially the main caretakers ${ }^{(19)}$.

In Brazil, family members still take over the role of caregivers without any assistance or support from 
effective Government programmes, which should supply grounds and guidance for the practice of this care ${ }^{(4)}$. It is well known that the hegemonic biomedical model is the pathological dimension of the situation, rather than the holistic view that includes the family as the unit to be cared for ${ }^{(2)}$. In this context, considering that the nursing profession has responsibilities and competences to act together with the caregivers, it becomes essential to assess the level of overload of these people and their influence on the dynamics of the family unit, which shall make it possible for the professional to identify more appropriate strategies for care-giving(3). It is up to the health teams to devote special attention to the caregivers helping to care for elderly people with $A D$, making all feel welcome, clarified and guided in relation to the responsibilities and rights ${ }^{(2)}$, making it easier for them to adapt to the new routine without cancelling out their own life and health needs(3).

\section{Conclusion}

The results of the present research show that the main caregivers for elderly patients with $A D$ have a higher overload than secondary carers, especially when we consider the activities related to routine assistance. This is because the main caregivers take on total or greater responsibility for provision of care, devoting a greater part of their time to assist the sick family member, while the secondary carer often limits the scope of care activities to the complementary activities and the provision of financial resources. With the confirmation of such differences in overload between the different groups of carers, attention is now given to the need to plan specific health actions for each type of caregiver, to reduce the overload of the family.

In relation to the limitations of this study, we mention, first and foremost, the low number of subjects in the sample, from the statistical standpoint; apart from heterogeneity in the composition of the groups, as certain pairs of individuals were providing care to one same elderly person, and there has been no prior identification of the stage of AD which the patients were experiencing, and which, if controlled, could provide more reliable results.

We therefore suggest new investigations about the different types of caregivers, with a greater number of participants and also the use of other instruments to assess the overload, and also qualitative studies that make it possible to top up the discussions about the issue and guide new approaches within the health area.

\section{References}

1. Almeida KS, Leite MT, Hildebrandt LM. Cuidadores familiares de pessoas portadoras de Doença de Alzheimer: revisão da literatura. Rev Eletr Enferm. [periódico da Internet]. 2009 [acesso 25 ago 2012]; 11(2): 403-12. Disponível em: http://www.fen.ufg.br/ revista/v11/n2/v11n2a23.htm.

2. Valim MD, Damasceno DD, Abi-acl LC, Garcia F, Fava SMCL. A doença de Alzheimer na visão do cuidador: um estudo de caso. Rev. Eletr. Enf. [periódico da internet]. 2010 [acesso 25 ago 2012]; 12(3): 528-34. Disponível em: http://www.fen.ufg.br/revista/v12/n3/ v12n3a16.htm.

3. Lenardt $\mathrm{MH}$, Willig $\mathrm{MH}$, Seima MD, Pereira LF. A condição de saúde e satisfação com a vida do cuidador familiar de idoso com Alzheimer. Colomb Med. 2011;42 Suppl:17-25.

4. Seima MD, Lenardt MH. A sobrecarga do cuidador familiar de idoso com Alzheimer. Texto Contexto Enferm. 2011;10(2):388-98.

5. Arruda MC, Alvarez AM, Gonçalves LHT. O familiar cuidador de portador de Doença de Alzheimer participante de um grupo de ajuda mútua. Cienc Cuid Saude. 2008;7(3):339-45.

6. Inouye K, Pedrazzani ES, Pavarini SCI, Toyoda CY. Life quality perception for the elderly with dementia and his/ her caregiver: evaluation and correlation. Rev. LatinoAm. Enfermagem. 2009;17(2):187-93.

7. Falcão SVD, Bucher-Maluschke FNSJ. Cuidar de familiares idosos com a doença de alzheimer: uma reflexão sobre aspectos psicossociais. Psicol Estud. 2009;14(4):777-86.

8. Diel L, Forster LMK, Kochhann R, Chaves MLF. Sociodemographic profile and level of burden of dementia patients' caregivers who participate in a support group. Dement Neuropsychol. 2010;4(3):232-7.

9. Simonetti JP, Ferreira JC. Estratégias de coping desenvolvidas por cuidadores de idosos portadores de doença crônica. Rev Esc Enferm USP. 2008;42(1):19-25. 10. Morais HCC, Soares AMG, Oliveira ARS, Carvalho CML, Silva MJ, Araujo TL. Sobrecarga e modificações de vida na perspectiva dos cuidadores de pacientes com acidente vascular cerebral. Rev. Latino-Am. Enfermagem. 2012;20(5):944-53.

11. Nogueira PC, Rabeh SAN, Caliri MHL, Dantas RAS, Haas VJ. Sobrecarga do cuidado e impacto na qualidade de vida relacionada à saúde de cuidadores de indivíduos com lesão medular. Rev. Latino-Am. Enfermagem. 2012;20(6):1048-56. 
12. Bandeira M, Calzavara MG, Varella A. Escala de Sobrecarga dos Familiares de Pacientes Psiquiátricos FBIS-Br: Adaptação Transcultural para o Brasil. J Bras Psiquiatr. 2005;54(3):206-14.

13. Pavarini SCI, Melo LC, Silva VM, Orlandi FS, Mendiondo MSZ, Filizola CLA, et al. Cuidando de idosos com Alzheimer: a vivência de cuidadores familiares. Rev Eletr Enferm. [periódico da Internet]. 2008 [acesso 27 ago 2012]; 10(3): 580-90. Disponível em: http://www. fen.ufg.br/revista/v10/n3/v10n3a04.htm.

14. Llibre Guerra JC, Guerra Hernández MA, Perera Miniet E. Impacto psicosocial del síndrome demencial en cuidadores cruciales. Rev Cubana Med Gen Integr. 2008;24(1):1-15.

15. Perdomo MP, Rodríguez JJL. Características sociodemográficas y nivel de sobrecarga de cuidadores de ancianos con Enfermedad de Alzheimer. Rev Cubana Enferm. 2010;26(3):104-16.

16. Cachioni C, Lima-Silva TB, Ordonez TN, GaloTiago J, Alves AR, Suzuki MY, et al. Elderly patients withAlzheimer's disease and their family relationships. Dement Neuropsychol. 2011;5(2):114-22.

17. Pinto MP, Barbosa DC, Ferreti CEL, Souza LF, Fram DS, Belasco AGS. Qualidade de vida de cuidadores de idosos com doença de Alzheimer. Acta Paul Enferm.2009;22(5):652-7.

18. Visser-Meily A, Post M, van de Port I, Maas C, Forstberg-Wärleby G, Lindeman E. Psychosocial functioning of spouses of patients with stroke from initial inpatient rehabilitation to 3 years poststroke. Stroke. 2009;40:1399-404.

19. Albuquerque EPT, Cintra AMO, Bandeira M. Sobrecarga de familiares de pacientes psiquiátricos: comparação entre diferentes tipos de cuidadores. J Bras Psiquiatr. 2010;59(4):308-16.

20. Freitas ICC, Paula KCCP, SoaresCJL, Parente ACM. Convivendo com o portador de Alzheimer: perspectivas do familiar cuidador. Rev Bras Enferm. 2008; 61(4):508-13.

21. Barroso SM, Bandeira M, Nascimento E. Fatores preditores da sobrecarga subjetiva de familiares de pacientes psiquiátricos atendidos na rede publica de Belo Horizonte, Minas Gerais, Brasil. Cad Saúde Publica. 2009;25(9):1957-68. 